\title{
Application of Tomato (Solanum lycopersicum) Leaf Volatiles as Antifungal Agents against Plant Pathogenic Fungi
}

\author{
Fumiyuiki Kobayashi ${ }^{1}$, Kenji Ishida ${ }^{2}$, Hiromi Ikeura ${ }^{2}$, Sachiko Odake ${ }^{1} \&$ Yasuyoshi Hayata $^{2}$ \\ ${ }^{1}$ Faculty of Appiled Life Science, Nippon Veterinary and Life Science University, Tokyo, Japan \\ ${ }^{2}$ School of Agriculture, Meiji University, Kanagawa, Japan \\ Correspondence: Hiromi Ikeura, School of Agriculture, Meiji University, 1-1-1 Higashimita, Tama, Kawasaki, \\ Kanagawa 214-8576, Japan. Tel: 81-44-934-7167. E-mail: hikeura@isc.meiji.ac.jp
}

$\begin{array}{lr}\text { Received: May 11, } 2012 & \text { Accepted: May 23, } 2012 \quad \text { Online Published: July 27, } 2012 \\ \text { doi:10.5539/jas.v4n8p231 } & \text { URL: http://dx.doi.org/10.5539/jas.v4n8p231 }\end{array}$

\begin{abstract}
The antifungal activity of tomato (Solanum lycopersicum) leaf volatiles (TLV), which are industrial residues, was investigated against three types of plant pathogenic fungi of Botryotinis fuckeliana, Glomerella cingulata and Fusarium oxysporum f. sp. melonis. The growth of B. fuckeliana and G. cingulata was completely inhibited by TLV extract volumes corresponding to 12 and $17 \mathrm{~g}$ of tomato leaves, respectively. The inhibition rate of a TLV extract volume corresponding to $17 \mathrm{~g}$ of tomato leaves against $F$. oxysporum $\mathrm{f}$. sp. melonis was approximately $55 \%$. The antifungal activity of TLV was thus shown to vary according to the type of plant pathogenic fungi. These results suggest the presence of a defense response against plant pathogenic fungi in tomato plants and that TLV are efficacious as a biological control agent.
\end{abstract}

Keywords: antifungal activity, tomato leaf volatiles, Botryotinis fuckeliana, Glomerella cingulata, Fusarium oxysporum f. sp. melonis

\section{Introduction}

In Japan, approximately 760,000 t of tomato fruit (Solanum lycopersicum L.) are produced per year, and the same amount of the leaves and stems, which are valuable organic resources, are grown. A part of it is used as compost, but largely-wasted. The beneficial use is big challenge, because wise use of resources and recycling is currently desired. Functional constituents in the plant can be used as food preservatives and biological control agents. In addition, it has been reported that the herbal aroma of plants differed according to the picking season and site, and that its antibacterial activity varied greatly (Angioni et al., 2006; Chorianopoulos et al., 2006). Thus, functional constituents in tomato leaves and stems may be used as antibacterial agents.

In recent years, consumers have shown a growing interest in food safety. Past treatment of agricultural crops with chemical pesticides has effectively ensured a stable supply of crops. However, there may be a risk of mammalian toxicity and environmental pollution by these chemical pesticides. Such chemical products remain in the crops and present a health hazard to farmers during growth and production and to consumers after harvest. Alternatives such as organic farming and pesticide-free production may be time consuming and ineffective in preventing damage by plant pathogens and insect pests. Use of biological control agents is an alternative non-chemical pest control method.

It is well known that tomato leaves have a characteristic odor (Buttery et al., 1987) and there are some reports about antifungal activity of the tomato leaf volatiles (TLV) (Zhang et al., 2008). The tomato cultivar 'Reiyo' used in this study is one of the main Japanese varieties of large-fruited tomatoes, although antifungal activity of the volatiles from leaves has not been studied yet. In this study, antifungal activity of TLV against the plant pathogenic fungi, Botryotinis fuckeliana, Glomerella cingulata and Fusarium oxysporum f. sp. melonis, was investigated.

\section{Materials and Methods}

\subsection{Materials}

The tomato cultivar 'Reiyo' (S. lycopersicum L.; Sakata Seed Co., Ltd., Yokohama, Japan) was cultured in a greenhouse at Meiji University from mid-August to mid-December 2007. Leaves from the fourth to the seventh flower clusters were sampled at the anthesis stage of the seventh flower cluster, frozen with liquid nitrogen, 
crushed, and stored at $-40^{\circ} \mathrm{C}$ until extraction of volatile compounds. The common fumigants, Chloropicrin (CP; Kanto Chemical Co., Ltd., Tokyo, Japan) and methyl isothiocyanate (MITC; Wako Pure Chemical Industries, Co., Ltd., Osaka, Japan), were used as positive controls. B. fuckeliana NBRC 9760, G. cingulata NBRC 5257 and F. oxysporum f. sp. melonis NBRC 6385 were purchased from the National Institute of Technology and Evaluation (Kisarazu, Japan).

\subsection{Extraction of Tomato Leaf Volatiles}

Volatile components were extracted from tomato leaves using the Porapak Q method (PQM) as described by Hayata et al. (2003). Crushed tomato leaves of $100 \mathrm{~g}$ fresh weight (FW) were centrifuged at $12,000 \mathrm{~g}$ for $20 \mathrm{~min}$, and the supernatant was filtered with a glass filter under reduced pressure. At room temperature, the extract was then poured into a PQ column (i.d. $2 \mathrm{~cm} \times 40 \mathrm{~cm}$ ) to absorb the volatile compounds on a PQ resin (polydivinylbenzene, 50-80 mesh, Waters Co., Ltd., Milford, MA, USA), and the column was then washed with $100 \mathrm{~mL}$ of distilled water. Following this, the volatile compounds were dissolved in $100 \mathrm{~mL}$ of diethyl ether (Kanto Chemical Co., Ltd.) to elute the absorbed compounds. The eluate containing the volatile compounds was dried over hydrous sodium sulfate (Kanto Chemical Co., Ltd.) overnight at room temperature and concentrated to $6 \mathrm{~mL}$ under a nitrogen stream.

\subsection{Measurement of the Antifungal Activity of TLV against Plant Pathogenic Fungi}

One hundred microliters of plant pathogenic fungal solutions $\left(10^{6}\right.$ spores $\left.\mathrm{mL}^{-1}\right)$ was plated on a potato dextrose agar plate (Difco, USA). Paper disks containing $\sim 1000 \mu \mathrm{L}$ of the extract were plated on inverted lids of the plates, and the extract was dried (Nishimura, 1995). The plates were then incubated at $25^{\circ} \mathrm{C}$ for 7 days after sealing with parafilm.

The antifungal activity of the extracts was calculated as the inhibition rate using the following equation;

$$
\text { Inhibition ratio }(\%)=\mathrm{d} / \mathrm{D} \times 100
$$

Where $\mathrm{d}$ is the diameter of the circular inhibition area $(\mathrm{mm})$ and $\mathrm{D}$ is the diameter of the plate $(85 \mathrm{~mm})$. All the experiments were performed in triplicate. Data are presented as means with standard errors.

\section{Results}

The antifungal activity of TLV against B. fuckeliana, G. cingulata and F. oxysporum f. sp. melonis is shown in Figure 1. The antifungal activity against all the plant pathogenic fungi tested increased linearly with an increase in the TLV extract volume. The growth of B. fuckeliana and G. cingulata was completely inhibited at TLV extract volumes corresponding to 12 and $17 \mathrm{~g}$ of tomato leaves, respectively. Inhibitory effects of TLV against $B$.

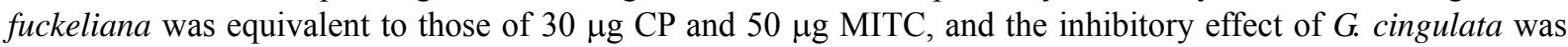
equivalent to those of $20 \mu \mathrm{g} \mathrm{CP}$ and $200 \mu \mathrm{g}$ MITC (Figure 2). CP and MITC had the high antifungal effects at low concentrations. In contrast, the inhibition rate of a TLV extract volume corresponding to $17 \mathrm{~g}$ of tomato leaves against F. oxysporum f. sp. melonis was approximately 55\%. The antifungal effect of TLV was therefore shown to vary according to the type of plant pathogenic fungi.

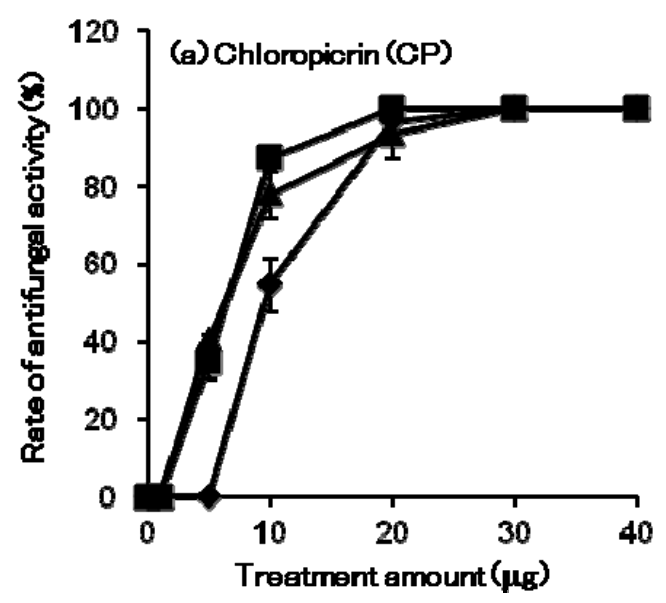




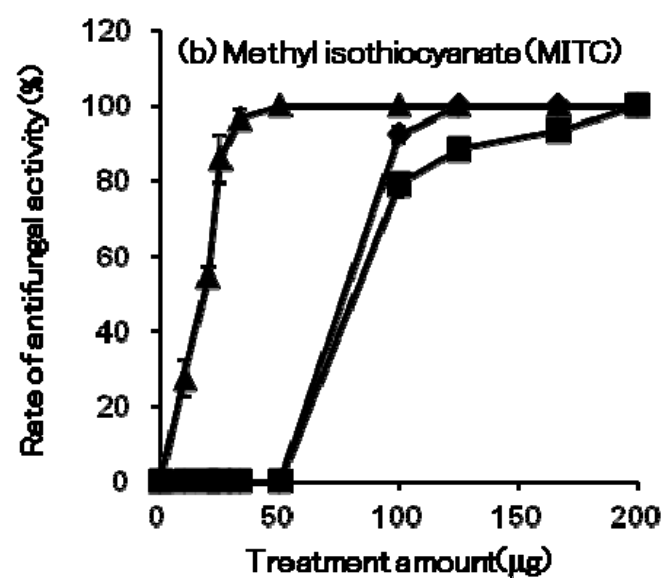

Figure 1. Antifungal activity of Chloropicrin and Methyl isothiocyanate against B. fuckeliana ( $\mathbf{\Delta})$, G. cingulata $(\mathbf{a})$, and F. oxysporum f. sp. melonis $(\diamond)$.

Data are presented as means with standard errors in triplicate.

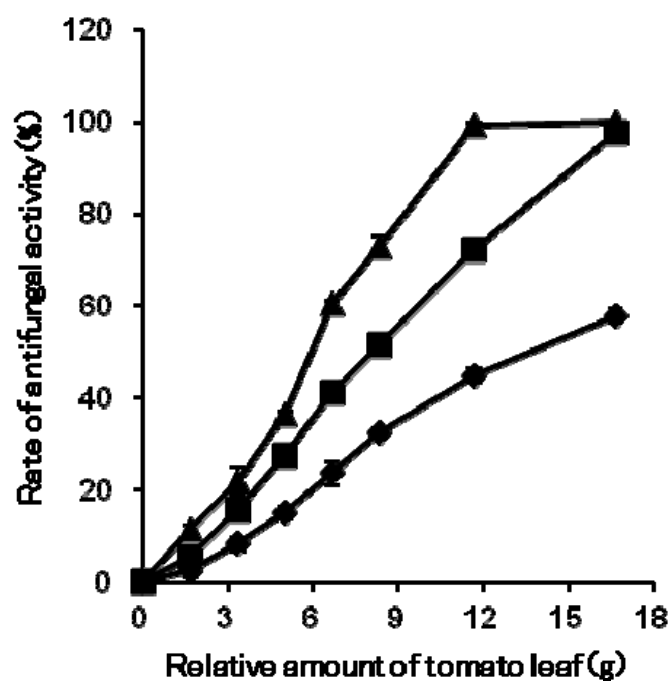

Figure 2. Antifungal activity of volatile extract from tomato leaves against B. fuckeliana ( $\mathbf{\Delta})$, G. cingulata (घ), and F. oxysporum f. sp. melonis $(\diamond)$.

Data are presented as means with standard errors in triplicate.

\section{Discussion}

The concentrations, at which CP and MITC were tested, were significantly higher than the $0.1 \mathrm{ppm}(8.5 \mu \mathrm{g} / 85$ $\mathrm{mL}$ in a petri dish) currently used in the industry. CP causes symptoms of poisoning (Kawai, 1973) and MITC is an irritant to the skin and mucous membranes (Uchiyama et al., 1992). Because equivalent results were obtained using lower levels of TLV, use of TLV as an alternative fumigant to CP and MITC should be considered.

The antifungal effect of TLV was therefore shown to vary according to the type of plant pathogenic fungi. Previous reports revealed that volatiles from thyme (Thymus vulgaris L.) showed strong antifungal activity against Aspergillus parasiticus and Cryptococcus neoformans but not against Candida albicans (Martos et al., 2007). In addition, no antifungal activity was observed in diethyl ether of the extract solvent (data not shown). In the present study, TLV exhibited strong antifungal activity, although $B$. fuckeliana infects tomato leaves and develops a disease. The inhibitory effect observed in this study may have been because of the higher concentration of TLV under experimental conditions.

$\mathrm{C}_{6}$-alcohols and -aldehydes known as green leaf volatiles (GLV), contain fresh green flavor. Rapid production of GLV within plants in response to insect damage and pathogen infection has been reported (Nakamura \& 
Hatanaka, 2002). Furthermore, GLV exhibits antibacterial activity against many types of microorganisms (Virginie et al., 2009). In the tomato plant, GLV was shown to be synthesized and released from the leaves because of insect damage by Helicoverpa armigera larvae (Rose et al., 1996). In the cotton plant, GLV production increased in the upper leaves because of feeding damage by Spodoptera exigua larvae in the lower leaves (Mann et al., 2000). These results suggest a resistant response system to insect damage or infection by plant pathogens in the tomato plant. In addition, it has been reported that essential oils exhibit antifungal activity at the three stages of conidial germination, growth of vegetative hyphae, and conidial formation (Inouye et al., 1998, 2001). However, whether or not TLV exhibit antifungal activity at any life cycle stage of plant pathogenic fungi remains unclear. In addition, the TLV involves the sesquiterpenes such as $\beta$-caryophyllene which high antifungal activity was reported (Huang et al., 2012) and alcohols such as geraniol and $\alpha$-linalool, which are known for antibacterial activity (Inoue, 2002), and these compounds have a deep relationship with antifungal activity of TLV.

\section{Conclusion}

In the present study, it suggested that volatiles from tomato leaves, which are usually scrapped, could be useful as a biological control agent. TLV showed a strong antifungal activity against three types of plant pathogenic fungi of B. fuckeliana, G. cingulata, and F. oxysporum f. sp. melonis, indicating a defense response against these plant pathogenic fungi. Further studies are needed to identify the antifungal compounds in the TLV, to investigate why antifungal activity of TLV varies with the variety of plant pathogenic fungi and to study the efficient recovery process of the TLV for practical use.

\section{References}

Angioni, A,. Barra, A., Coroneo, V., Dessi, S., \& Cabras, P. (2006). Chemical composition, seasonal variability and antifungal activity of Lavandula stoechas L. ssp. stoechas essential oils from stem/leaves and flowers. J. Agric. Food Chem., 54, 4364-4370. http://dx.doi.org/10.1021/jf0603329

Buttery, R. G., Ling, L. C., \& Light, D. M. (1987). Tomato leaf volatile aroma components. J. Agric. Food Chem., 35, 1039-1042.

Chorianopoulos, N., Evergetis, E., Mallouchos, A., Kalpoutzakis, E., Nychas, G. J., \& Haroutounian, S. A. (2006). Characterization of the essential oil volatiles of Satureja thymbra and Satureja parnassica: Influence of harvesting time and antimicrobial activity. J. Agric. Food Chem., 54, 3139-3145. http://dx.doi.org/10.1021/jf053183n

Hayata, Y., Sakamoto, T., Chamorn, M., Kozuka, H., \& Sakamoto, K. (2003). Application of the porapak Q column extraction method for tomato flavor volatile analysis. J. Agric. Food Chem., 50, 3401-3404. http://dx.doi.org/10.1021/jf0209950

Huang, M., Sanchez-Moreiras, A. M., Abel, C., Sohrabi, R., Lee, S., Gershenzon, J., \& Tholl, D. (2012). The major volatile organic compound emitted from Arabidopsis thaliana flowers, the sespuiterpene (E)- $\beta$-caryophyllene, is a defense against a bacterial pathogen. New Phytologist, 193, 997-1008. http://dx.doi.org/10.1111/j.1469-8137.2011.04001.x

Inoue, S. (2002). Biseibututokaori. Fragrance journal Ltd., p.188-193.

Inouye, S., Watanabe, M., Nishiyama, Y., Takeo, K., Akao, M., \& Yamaguchi, H. (1998). Antisporulating and respiratory-inhibitory effects of essential oils on filamentous fungi. Mycoses, 41, 403-410.

Inouye, S., Uchida, K., \& Yamaguchi, H. (2001). In-vitro and in-vivo anti- Trichophyton activity of essential oils by vapour contact. Mycoses, 44, 99-107. http://dx.doi.org/10.1046/j.1439-0507.2001.00618.x

Kawai, M. (1973). Inhalation toxicity of phosgene and trichloronitromethane (Chloropicrin). Sangyoigaku, 15, 60-61.

Mann, C. M., Cox, S. D., \& Markham, J. L. (2000). The outer membrane of Pseudomonas aeruginosa NCTC 6749 contributes to its tolerance to the essential oil of Melaleuca alternifolia (tea tree oil). Let. Appl. Microbiol., 30, 294-297.

Martos, M. V., Navajas, Y. R., Lopez, F., \& Perez-Alvarez, J. A. (2007). Antifungal activities of thyme, clove and oregano essential oils. J. Food Safety, 27, 91-101. http://dx.doi.org/10.1111/j.1745-4565.2007.00063.x

Nakamura, S., \& Hatanaka, A. (2002). Green-leaf-derived $\mathrm{C}_{6}$-aroma compounds with potent antibacterial action that act both on gram-negative and gram-positive bacteria. J. Agric. Food Chem., 50, 7639-7644. http://dx.doi.org/10.1021/jf025808c 
Nishimura, T. (1995). Shokubutuseiyujoukinosatukabikassei. Aromatopia, 10, 60-63.

Rose, U., Manukian, A., Heath, R. R., \& Tumlinson, J. H. (1996). Volatile semiochemicals released from undamaged cotton leaves-a systemic response of living plants to caterpillar damage. Plant Physiol., 111, 487-495.

Uchiyama, S., Takeda, H., Kobayashi, A., Ito, S., Sakurai, H., Tada, Y., ... Saito, Y. (1992). Determination of methyl isothiocyanate in wine by GC and GC/MS. Syokuhin Eiseigaku Zasshi, 33, 603-608.

Gosset, V., Harmel, N., Gobel, C., Francis, F., Haubruge, E., Wathelet, J. P., .. Fauconnier, M. L. (2009). Attachs by a piercing-sucking insect (Myzus persicae Sultzer) or a chewing insect (Leptinotarsa decemlineata Say) on tomato plants (Solanum lycopersicum L.) induce differential changes in volatile compound release and oxylipin synthesis. J. Exp. Bot., 60, 1231-1240. http://dx.doi.org/10.1093/jxb/erp015

Zhang, P. Y., Chen, K. S., He, P. Q., Liu, S. H., \& Jiang, W. F. (2008). Effects of crop development on the emission of volatiles in leaves of Lycopersicon esculentum and its inhibitory activity to Botrytis cinerea and Fusarium oxysporum. J. Integr. Plant Biol., 50, 84-91. http://dx.doi.org/10.1111/j.1744-7909.2007.00597.x 